\title{
Macrophage Clearance of Apoptotic Cells: A Critical Assessment
}

\author{
Siamon Gordon ${ }^{1,2 *}$ and Annette Plüddemann ${ }^{3}$ \\ ${ }^{1}$ College of Medicine, Graduate Institute of Biomedical Sciences, Chang Gung University, Taoyuan City, Taiwan, ${ }^{2}$ Sir William \\ Dunn School of Pathology, University of Oxford, Oxford, United Kingdom, ${ }^{3}$ Nuffield Department of Primary Care Health \\ Sciences, University of Oxford, Oxford, United Kingdom
}

As the body continues to grow and age, it becomes essential to maintain a balance between living and dying cells. Macrophages and dendritic cells play a central role in discriminating among viable, apoptotic, and necrotic cells, as selective and efficient phagocytes, without inducing inappropriate inflammation or immune responses. A great deal has been learnt concerning clearance receptors for modified and non-selfligands on potential targets, mediating their eventual uptake, disposal, and replacement. In this essay, we assess current understanding of the phagocytic recognition of apoptotic cells within their tissue environment; we conclude that efferocytosis constitutes a more complex process than simply removal of corpses, with regulatory interactions between the target and effector cells, which determine the outcome of this homeostatic process.

OPEN ACCESS

Edited by:

Amiram Ariel,

University of Haifa, Israel

Reviewed by: Dror Mevorach,

Hadassah Medical Center, Israe Sylvain Perruche,

Institut National de la Santé et de la Recherche Médicale, France

${ }^{*}$ Correspondence:

Siamon Gordon

siamon.gordon@path.ox.ac.uk

Specialty section:

This article was submitted to

Molecular Innate Immunity, a section of the journal

Frontiers in Immunology

Received: 29 September 2017

Accepted: 16 January 2018

Published: 30 January 2018

Citation:

Gordon S and Plüddemann A (2018) Macrophage Clearance of Apoptotic

Cells: A Critical Assessment.

Front. Immunol. 9:127.

doi: 10.3389/fimmu.2018.00127
Keywords: apoptosis, apoptotic cells, clearance of apoptotic cells, phagocytosis, macrophages

\section{INTRODUCTION}

Programmed cell death, apoptosis, is closely linked to recognition and clearance by phagocytosis, resulting in anti-inflammatory and compensatory growth responses during fetal and adult life. Prolonged or incomplete containment and destruction during the apoptotic process can merge into secondary necrosis to bring about pro-inflammatory and pathological responses by phagocytes that are still poorly understood. Many aspects of this process are covered in excellent reviews by leading investigators, including Henson (1), Arandjelovic and Ravichandran (2), Nagata and Tanaka (3), Lim et al. (4), and their colleagues, which should be consulted for detailed exposition. We have previously reviewed the process of phagocytosis in relation to infection and microbial recognition (5), emphasizing its cell biology in model systems. We focus here on clearance of apoptotic cells in situ by heterogeneous tissue mononuclear phagocytes, in health and disease.

\section{A BRIEF HISTORY}

Although current nomenclature settled around the early reports by Wyllie et al. (6), the observations of cell death in its many manifestations date back to the nineteenth century, from descriptions

\footnotetext{
Abbreviations: AIP, apoptosis-induced proliferation; DC, dendritic cell; Gas 6; growth arrest specific protein 6; GPCR, G protein-coupled receptor; IECs, intraepithelial cells; IGF-1, insulin-like growth factor-1; KLF, Kruppel-like factor; LPS, lipopolysaccharide; LXR, liver X receptor transcription factor; MPS, mononuclear phagocyte system; MerTK, proto-oncogene c-mer tyrosine kinase; Megf8, milk fat globule-EGF factor 8 (lactadherin); MNGC, multinucleated giant cell; NET, neutrophil extracellular trap; PGE2, prostaglandin E2; ProS1, gene for protein S(eattle); PRRs, pattern-recognition receptors; PS, phosphatidyl serine; PPAR, peroxisome proliferator activator receptor transcription factor; ROS, reactive oxygen species; SLE, systemic lupus erythematosus; TAM, tyrosine receptor kinases Tyro 3, Axl and MerTK; TLR, toll-like receptor; TNF, tumour necrosis factor; tgf beta, transforming growth factor beta.
} 
by Virchow, Metchnikoff, and many pathologists. Wallach et al. have provided an instructive time line of concepts of tissue injury and cell death in inflammation (7). An historic perspective of macrophages, phagocytic mechanisms, and lysosomal digestion is provided elsewhere $(5,8)$. The pre-eminent role of tissue macrophages in clearance was emphasized in the twentieth century, as a primary function of the reticuloendothelial system, subsequently renamed the mononuclear phagocyte system (MPS) (9). Studies in Caenorhabditis elegans (10) stimulated genetic dissection of apoptosis and clearance by epithelial cells in organisms that lack "professional" phagocytes; important discoveries of macrophage clearance followed in Drosophila and other model organisms, such as zebra fish and mice. Uptake of dead cells by non-professional phagocytes in vertebrates became overshadowed by emphasis on macrophages and related dendritic cells (DCs), although recent studies (2) have to some extent redressed the balance; turnover of photoreceptors by retinal pigment epithelia and of aberrant sperm in the testis by Sertoli cells are highly active functions of non-hematopoietic phagocytic cells, and uptake of cell corpses has also been demonstrated in epithelia, fibroblasts, astrocytes, and cancer cells, the so-called non-professional phagocytes (11). Different terms have emerged for a range of distinct though related processes, in addition to efferocytosis (12); these include necroptosis (13), pyroptosis (14), phagoptosis (15), ferroptosis (16), trogocytosis (17), and entosis (18), depending on one or other characteristic feature. Mevorach and colleagues have introduced clarity into the terminology of this expanding topic, which will be defined as relevant, below (19). Henson and Bratton (20) provided early evidence that clearance of programmed apoptotic cell death by macrophages gave rise to anti-inflammatory effects, unlike the pro-inflammatory consequences of the uptake of necrotic cells, which could follow at a further stage of programmed cell death, during infection or as a result of accidental injury. Another time line of particular interest in this area is given by Nagata and Tanaka, who pioneered the role of phosphatidyl serine (PS) and membrane lipid reorganization in the recognition of apoptotic cells (3).

The physiological roleofapoptoticcell clearancebymacrophages has been documented in organ development, tissue remodeling, e.g., in the uterus and mammary gland, repair and potential cell replacement following injury and, in a few species, regeneration of complex organs. In pathology, monocytes, macrophages, and DCs are important contributors to inflammation and its resolution, following disposal of necrotic corpses and subcellular constituents, e.g., during infection, innate and autoimmunity, atherogenesis, and malignancy. Many authors have considered cell death, its recognition, disposal, and regulation as central homeostatic functions of the MPS; aspects of this topic are reviewed by the various contributors to this Frontiers of Immunology collection, cited as available at the time of writing $(21,22)$. We shall not deal in this review with the mechanisms of cell death itself.

\section{MONONUCLEAR PHAGOCYTES ARE HIGHLY HETEROGENEOUS}

The cells of the mammalian MPS constitute a widely dispersed population derived from common hematopoietic progenitors, which are distinct in the embryo and adult (23). Tissue-resident macrophage populations in the fetus are distributed from yolk sac and fetal liver precursors from mid gestation, and turn over locally to a variable extent throughout adult life (24). From birth, bone marrow-derived monocytes are recruited to replenish and supplement tissue macrophage populations in the steady state, and in response to inflammatory, metabolic, infectious, and malignant disease processes, as required. Circulating mononuclear cells contain precursors of macrophages, DCs, and osteoclasts, and subpopulations of monocytes that are characterized by distinct marker antigens and receptors (25). Recent single cell RNA analysis has revealed additional mononuclear cell subpopulations in blood without functional characterization (26). Trahtemberg and colleagues identified two human blood monocyte-derived DC subpopulations which differ in their expression of surface markers, phagocytic clearance, and responses to the uptake of apoptotic cells (27). The markedly heterogeneous mononuclear phagocytes in tissues display the ability to phagocytose particulates to a variable extent, depending on their differentiation, recruitment, and activation by tissue-specific and microbial stimuli. The ability of neutrophils which are highly phagocytic for opsonized microbes, and of eosinophils, basophils, and mast cells, to phagocytose apoptotic targets has been less studied. In addition, MPS cells variably display fluid phase, macropinocytic, and receptor-mediated endocytosis, which contribute to their clearance of solutes and smaller particulates. In response to local need, resident macrophages can migrate from adjacent reservoirs, as elegantly demonstrated through in vivo experiments by the groups of Wang and Kubes and Robbins, respectively, in liver (28) and heart (29). The prototypic and organ-specific phagocytic activity of the mixed populations of macrophages in different organs differ considerably, as shown by elegant clearance experiments in vivo, described in detail below $(30,31)$. Fusion of monocytes and macrophages gives rise to the formation of osteoclasts in bone and of multinucleated giant cells (MNGCs) in granulomatous diseases (32). We have demonstrated a striking difference in the phagocytosis of a range of particulates, including latex and complement-, but not antibody-opsonized sheep erythrocytes by IL4/13 cytokine-induced MNGC (33). Finally, activation of macrophages by innate and Th1 - and Th2-dependent adaptive immune stimuli induces a spectrum of changes in cellular phenotype, including cytocidal and phagocytic capacity (34), hitherto mainly studied in vitro.

\section{MYELOID CELL TURNOVER}

Myeloid leukocytes themselves undergo apoptosis and necrosis, as well as inducing these processes in a range of target cells. We therefore briefly consider aspects of their own turnover, clearance, and mechanisms of death that may be relevant to subsequent consequences. Recent studies by Yona and colleagues have established the circulation time and precursor-product relationships of different human monocyte subsets (35). Macrophages can become long-lived, terminally differentiated tissue-resident cells which remain biosynthetically active while ceasing to proliferate, but recently recruited monocytes and activated macrophages and DC themselves can undergo apoptosis within days of responding to 
inflammatory and infectious stimuli. By comparison, neutrophils are short lived and readily proceed from apoptosis to secondary necrosis when activated during acute inflammation; eosinophils may survive longer in tissues than usually appreciated. The microbicidal and cytocidal activities of activated neutrophils and monocyte/macrophages depend on generation of reactive radicals derived from oxygen through a respiratory burst; in addition, degranulation by neutrophils and eosinophils releases potent neutral proteinases such as elastase, as well as myeloperoxidase, to initiate cytotoxicity, whereas interferon gamma activated macrophages contribute to target cell killing by release of nitrogen metabolites generated by inducible nitric oxide synthase. Other mechanisms of myeloid cell cytotoxicity include chromatin extracellular trap (neutrophil extracellular trap) production by neutrophils and probably activated macrophages and release of tumour necrosis factor (TNF)alpha. Inflammasome activation and IL-1 release depend on selected proteolysis by cytosolic caspases. Depletion of essential amino acids such as tryptophan and arginine in their local environment contribute to cell death.

\section{INTERACTIONS BETWEEN MACROPHAGES AND APOPTOTIC CELLS}

We have outlined the heterogeneity of the macrophage populations involved in clearance, and the complexity of their potential apoptotic/necrotic cargo. It has become customary to break the overall process down into distinct stages: "find me" $(36,37)$, by chemokine-receptor attractants and plexin-semaphorin guidance/repulsion (38, 39); "eat me" (40) and "don't eat" me (41) signals between apoptotic cells and phagocytes, involving diffusible products, plasma components such as thrombospondin, and intercellular interactions. We focus here on recognition (42) by macrophages of well-defined apoptotic cells. Apart from the welldocumented chromatin and cytoplasmic changes, we consider PS (43) and other potential ligands expressed on the surface of senescent and apoptotic cells and the wide range of direct and indirect opsonic receptors expressed on the macrophage surface (Figure 1). This information is based mainly on in vitro studies, with some support obtained from mouse and other genetic models in vivo. Phagoptosis, the uptake of viable cells (15), resulting in their destruction, depends on exposure of "eat me" and/or loss of "don't eat me" signals; it mediates turnover of erythrocytes, neutrophils, and other cells, and also contributes to defense against infection.

Several aspects of our present understanding deserve further comment: there is a bewildering range of possible molecular interactions reported in this literature, depending to a large extent on the interests of the researcher rather than proven relative importance under different conditions in vivo. It is perhaps not surprising that so critical a housekeeping function should involve considerable redundancy; it is well known that inhibitors or ablation of favorite individual receptor-ligand pairs are at best only partial in their effect in vitro, and often undetectable in vivo. For example, this was found in our own studies of possible SR-A involvement in the thymus, a site of avid apoptotic thymocyte clearance by macrophages (44). Up to a point, one could argue that some of these candidates could act in a common pathway or be redundant. A more likely interpretation is that there is organ-specific involvement of particular receptorligand pairs, as indicated by new evidence, discussed in more detail below. Furthermore, most previous studies have failed to appreciate the modulation of phagocytic activity by physiological and pathological regulation of particular pathways in different tissue environments. We should expect wide variation from the experimental use of species as divergent as Drosophila, zebra fish, mouse, and man, with clearance mechanisms arising by convergent as well as divergent evolution. Finally, since different cell types can perform the same function, constitutively or after induction, it is essential to identify the particular cells involved by cell-specific deletion in any experimental model; for example, this was demonstrated by Ravichandran and colleagues in a receptor transgenic overexpression model which showed enhanced clearance was attributable to epithelial cells and not macrophages, as might have been assumed (45). The macrophage ablation studies during development, e.g., in PU-1 null mice (46) show remarkably little impact except for minor deficiencies in interdigital web regression; presumably, alternative mesenchymal cells can compensate for developmental clearance of apoptotic cells. Failure to clear erythrocyte nuclei, however, does create hemodynamic problems after birth and early death postnatally can also be ascribed to infection.

\section{MECHANISMS OF CLEARANCE OF APOPTOTIC CELLS BY MACROPHAGES}

We have previously outlined some of the broad features of opsonic, antibody, and complement-mediated phagocytosis (5), the phagocytic synapse model based on Dectin-1 mediated uptake of yeast particles (47), and a kinetic exclusion model of other plasma membrane molecules during uptake (4); its relevance to the mechanism of apoptotic cell uptake has not been determined. Intravital microscopy has revealed striking recruitment of different mononuclear cell populations during development (48) and following sterile and infectious injury and repair (28). Phosphatidylinositol kinases play an important role in signaling and ingestion of apoptotic cells (49). Various phosphoinositide mediators derive from preformed membrane phospholipids and reorganization of lipids within the plasma membrane bilayer with resultant PS exposure on the outer surface, as elucidated by the groups of Nagata and Tanaka (3) and Kay and Grinstein (50). BAI-1, an adhesion G protein-coupled receptor $(51,52)$, mediates uptake of apoptotic cells via PS recognition, followed by Dock and Elmo signaling. Effects of apoptotic cell uptake on membrane traffic, vesicular fusion and fission, the role of small GTPases, phagosome formation and function (53), as well as possible interactions with autophagy require further investigation. Similarly, there is need for more studies on the effects of apoptotic cell uptake on gene and protein expression, for example, by in situ hybridization and multiplex histochemistry, as well as of posttranslational and epigenetic modifications, in heterogeneous cell populations and individual macrophages, in vivo and in vitro. 


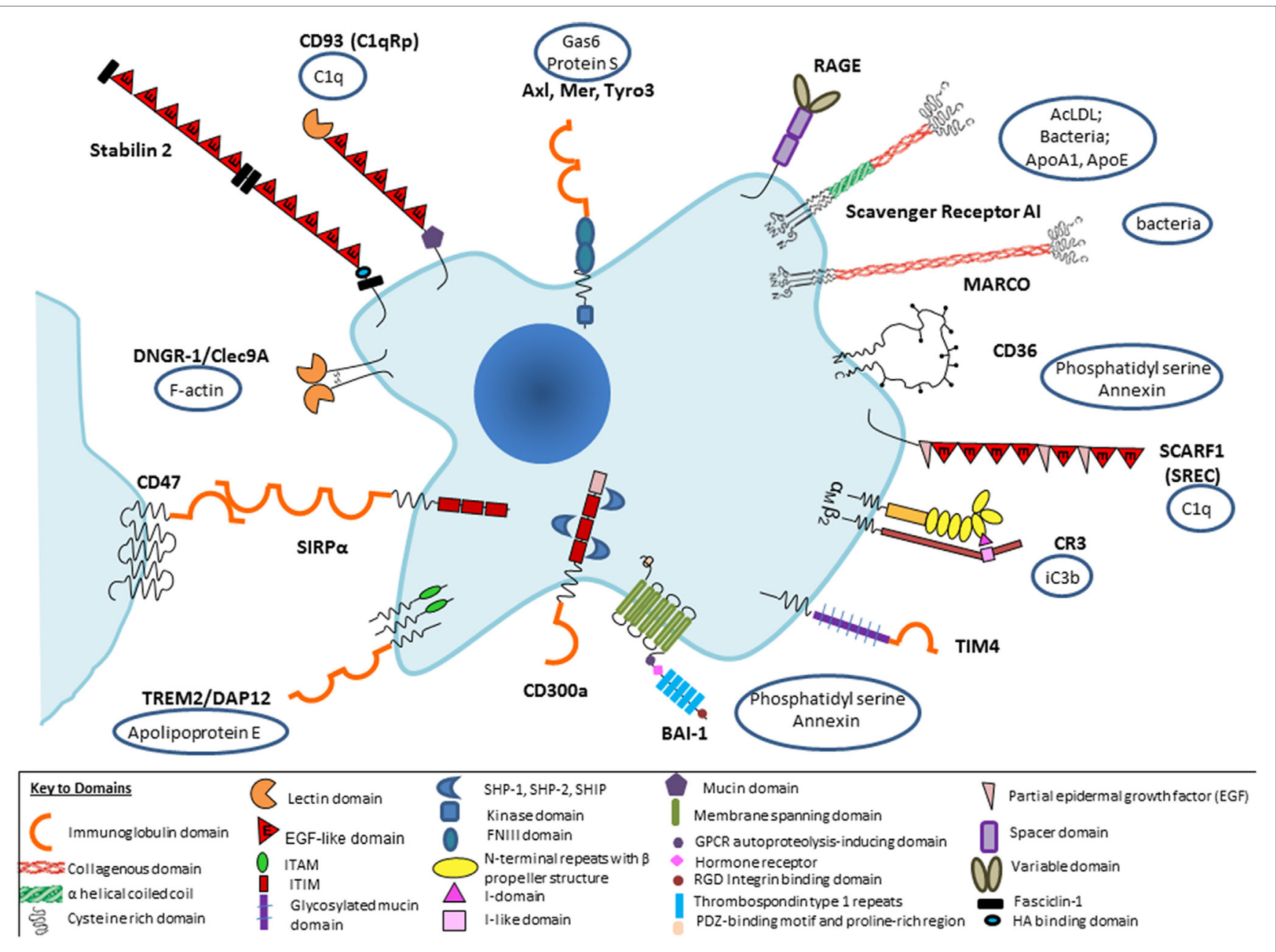

FIGURE 1 | Selected macrophage phagocytic receptors and ligands implicated in apoptotic cell clearance. Receptor-ligand interactions can be direct or indirect, via opsonic intermediates derived from plasma or tissue sources. Macrophage receptors such as CD11b/CD18 can bind via opsonic complement components, including secretion products of macrophages themselves, or promiscuously to other ligands, so that it becomes difficult to classify as direct or indirect.

\section{CLEARANCE OF APOPTOTIC CELLS BY RESIDENT TISSUE MACROPHAGES IN VIVO}

It has been known for some time that resident macrophage populations in different organs such as liver, gut, lung, bone marrow, spleen, and brain are heterogeneous in their morphology, turnover, and antigen expression profile. Gene expression studies by Lavin and colleagues have documented organ-specific gene and enhancer patterns, as well as canonical signatures for a range of tissue macrophage populations (54). Apoptotic cell clearance is mediated by distinct pathways in different organs and helps to shape the local phenotype, as shown by recent studies by the groups of Hidalgo (31) and Magarian Blander (30). A-Gonzalez and colleagues used a parabiotic model to study homeostatic leukocyte clearance in vivo. Distinct receptors, opsonins, and transcription factors were demonstrated in uptake by macrophages in the bone marrow, spleen, intestine, liver, and lung interstitium; alveolar macrophages in the lung were not accessed by blood delivery. Mutant mice deficient in milk fat globule-EGF factor 8 (lactadherin), liver $\mathrm{X}$ receptor transcription factor alpha/beta, peroxisome proliferator activator receptor transcription factor gamma, and proto-oncogene c-mer tyrosine kinase (MerTK) differed from wild-type controls and varied in their contribution to uptake in bone marrow, spleen, and liver. Annexin A1 and Timd4 were also utilized to determine tissue-specific dynamics and expression of different phagocytic mediators. Gene expression analysis demonstrated preservation of distinct core signatures, but phagocytosis imprinted a distinct anti-inflammatory profile, upregulation of CD163 and of CD206, the macrophage mannose receptor, and decrease of the pro-inflammatory expression of IL-1 beta. Expression of CD206 made it possible to identify phagocytic macrophages in the steady state in the absence of experimental manipulation. Clearance activity confirmed the diurnal rhythm of neutrophil turnover. Several interesting aspects of this study require further study: the role of variation in apoptotic rate in neutrophils, the impact of non-circulating apoptotic cells, e.g., generated in the thymus by dexamethasone treatment, and the 
absence of detectable annexin binding in some experiments, consistent with uptake and subsequent killing of viable cells by phagoptosis. Furthermore, the effects of concurrent inflammation and infection on the clearance of apoptotic as well as necrotic cells, add an additional layer of complexity.

The study by Cummings et al. used a different genetic strategy to study the effects of apoptosis in a single organ, the small intestine, on gene expression by macrophages and DC, after uptake of dying epithelial cells (30). Diphtheria receptor expression in mice was targeted to the intestine by a villin construct with an eGFP reporter; low dose diphtheria toxin induced synchronous apoptosis selectively to ileum epithelium without affecting barrier function. Five subpopulations of APC were isolated before and after apoptosis by FACS, and gene expression was analyzed. Two $\mathrm{CD}_{64}{ }^{+}$macrophages and one CD $24^{+}$DC population were shown to display distinctive signatures after phagocytosis of apoptotic cells; the macrophage signatures included lipid metabolism and aromatic amino acid catabolism, whereas the DC subset program was consistent with activation of regulatory $\mathrm{CD}^{+}$lymphocytes. A common signature of suppression of inflammation consisted of distinct genes in macrophages and DCs. Only the DCs were induced by apoptotic intraepithelial cell (IEC) uptake to migrate to draining lymph nodes and found able to induce immunological tolerance. Several of the differentially induced genes in phagocytes overlapped with susceptibility genes for inflammatory bowel disease. $\mathrm{CD} 103^{+} \mathrm{CD} 11 \mathrm{~b}^{+}$and distinct $\mathrm{CD} 11 \mathrm{~b}^{+}$only macrophages, which sampled the majority of apoptotic $\mathrm{IEC}^{+}$, upregulated growth arrest specific protein 6 , Cd 163, and MerTK genes, whereas CD $103^{+}$DC expressed the gene for CD105, a member of the mannose receptor family. Other differentially expressed genes included those implicated in apoptotic cell clearance, enhanced anti-inflammatory, and reduced pro-inflammatory pathways.

A recent study by Roberts et al. (55) demonstrated that selected tissue-resident macrophages in the peritoneal and pleural cavities, and lung alveolar space, are locally programmed for silent clearance of apoptotic cells. Specific populations of macrophages clear apoptotic cells in different tissues; they share features that limit recognition of nucleic acids in response to signals from their local tissue microenvironment. The transcription factor Krüppel-like factor-2 (KLF2), and to a lesser extent KLF4, control the expression of many genes within the macrophage clearance program. These characteristics include high expression of receptors for apoptotic cells such as Tim4, but low expression of toll-like receptor (TLR) 9 and reduced TLR responsiveness to nucleic acids. The environmental signals in different tissues, which are unknown, can override inflammatory stimulation and are lost when cells are isolated, in vitro. Other tissue-resident macrophages vary in their inhibition of inflammatory responses after apoptotic cell uptake, and it is unclear how homeostasis is maintained in the face of infection, or restored during resolution of inflammation.

Similarly, Baratin et al. reported that a population of $\mathrm{CX} 3 \mathrm{CR} 1^{+} \mathrm{CD} 64^{+} \mathrm{MerTK}^{+} \mathrm{CD} 11 \mathrm{c}^{+}$resident macrophages, but not CD8alpha DC, were the main local efferocytic cells in the $\mathrm{T}$ zone of lymph nodes; however, these scavenger macrophages did not prime CD4 T cells efficiently, unlike DC (56). Tingible body macrophages, prominent in germinal centers in lymph nodes, spleen, and other lymphoid structures, clear apoptotic B lymphocytes. Their possible role in B lymphocyte affinity maturation and antibody diversification and interactions with follicular DCs and other mesenchymal stromal cells require further investigation (57).

\section{ROLE OF PHAGOCYTIC CLEARANCE OF DYING CELLS IN INFLAMMATION AND ITS RESOLUTION, TISSUE GROWTH, AND IMMUNE REGULATION}

The uptake of apoptotic cells by macrophages is not "silent," but anti-inflammatory. Secretory mediators include cytokines [transforming growth factor beta (tgf beta), IL-10] and arachidonate metabolites, e.g., prostaglandin E2, as well as a range of proresolving mediators. Addition of macrophages that have ingested early apoptotic cells, to lipopolysaccharide (LPS)-induced inflammatory cells in vitro or in vivo, reduced inflammatory pathways (20), whether through the above mediators or by undefined direct contact mechanisms. However, genome wide gene expression, proteomic and metabolomic studies may yield a more complex picture of pro- and anti-inflammatory signature markers which should be reinvestigated by newly developed population and single cell methods. In vitro studies need to take into account the tolerogenic and pro-inflammatory subtypes of macrophages and DC, the nature of the apoptotic cell targets, clearance receptor usage, and possible association with TLR. Previous exposure to priming agents, including apoptotic cells themselves, can convert the response to a secondary challenge (58). The in vivo studies described above have provided evidence for "imprinting," comparable to "trained immunity" (59), of an anti-inflammatory phenotype in several different tissues, but further studies are needed in the presence of infection or trauma, and associated cell death.

Studies in Drosophila (48) and a range of vertebrates have implicated macrophages in the replacement of epithelial and other cells during development and in tissue repair after wounding. Apoptosis and proliferation of microglia are coupled in the adult brain (60). Dying cells themselves are able to generate recruiting and mitogenic signals to attract and interact reciprocally with macrophages. These include a range of trophic factors such as insulin-like growth factor-1 (IGF-1) (45) and TNF-related cytokines (61), released after phagocytic clearance. Extracellular reactive oxygen species (ROS) produced by epithelial disk cells drive apoptosis-induced proliferation via Drosophila macrophages (61). The Ravichandran group has shown that IGF-1 released by macrophages in response to uptake of apoptotic cells, can inhibit apoptotic cell clearance by neighboring epithelial cells, while enhancing their uptake of smaller vesicles (45). Ueno et al. showed that CX3CR $1^{+}$microglia were required for survival of selected cortical neurons during development, ascribed to IGF-1 production after uptake of apoptotic neurons (62). Conversely, Brown and Neher have postulated that microglial phagoptosis mechanisms contribute to neuronal loss, synaptic sculpting, and loss of neuronal processes during development and neurodegeneration (63). 
A striking example of the link between phagocytic clearance by macrophages and cell growth and differentiation was demonstrated by Kawane et al. (64). DNAse II in macrophages is responsible for destruction of nuclear DNA from erythroid precursors after enucleation, and essential for definitive erythropoiesis in mouse fetal liver. Recent studies by Fearnhead et al. have shown that Ferroptosis, a regulated physiological cell death process which requires free ferrous iron, occurs through $\mathrm{Fe}(\mathrm{II})$-dependent lipid peroxidation when the reduction capacity of a cell is insufficient (16). Most studies have not distinguished between apoptotic, anti-inflammatory and immunomodulatory, versus pro-inflammatory, necrotic targets, or the source of contact-dependent, vesicular, or soluble products such as ROS and lipid metabolites. The nature of the apoptotic stimulus, for example, programmed versus $\mathrm{X}$-ray-induced cell death, the heterogeneity of mononuclear phagocyte populations, and the local tissue environment can all contribute to the outcome. Most striking is the regenerative capacity of species such as axolotls (65) after limb amputation, for example, which depends on early recruitment and engulfment by phagocytic macrophages (66). A recent comprehensive analysis of gene expression during regeneration of the axolotl limb provides a resource to identify critical genes (67).

Dying cells release a complex mixture of lipids, oxidized phosphoryl choline derivatives, which can display opposing activities, interfering with TLR signaling to prevent inflammatory responses, while hyperactivating DCs and macrophages to promote inflammation by IL-1. CD14, the microbial LPS receptor, expressed by monocytes and macrophages, and downregulated by DC, is an early central regulator of both activities (68). Zanoni et al. demonstrated further that isolated lipid constituents of the mixture induce inflammasome-dependent macrophage hyperactivation via CD14, without compromising macrophage viability, thus promoting inflammation in sepsis, but not lethality.

IL-4 and other Th2 cytokines, possibly of innate sources, induce growth and an alternative activation pathway of macrophages, which has been implicated in wound repair (32). The macrophage mannose receptor (CD206), one of the characteristic signature genes induced by IL-4, is upregulated in mouse models of intestinal apoptosis, in which there is regeneration of epithelium, although it has not been determined whether it is required. A recent study has shown that apoptotic cell phagocytosis selectively amplifies the gene signature induced in macrophages by IL-4/13 (69). The tyrosine receptor kinases Tyro 3, Axl, and MerTK (TAM) receptors and their ligands play distinct immunoregulatory roles in DCs and macrophages (70) (Figure 2). Tyro3 and gene for protein S(eattle) mediate a negative feedback loop between DC and activated Th2 lymphocytes to inhibit type 2 immunity (71); by contrast, Mer-TK and Axl on macrophages require a local apoptotic ligand to promote a

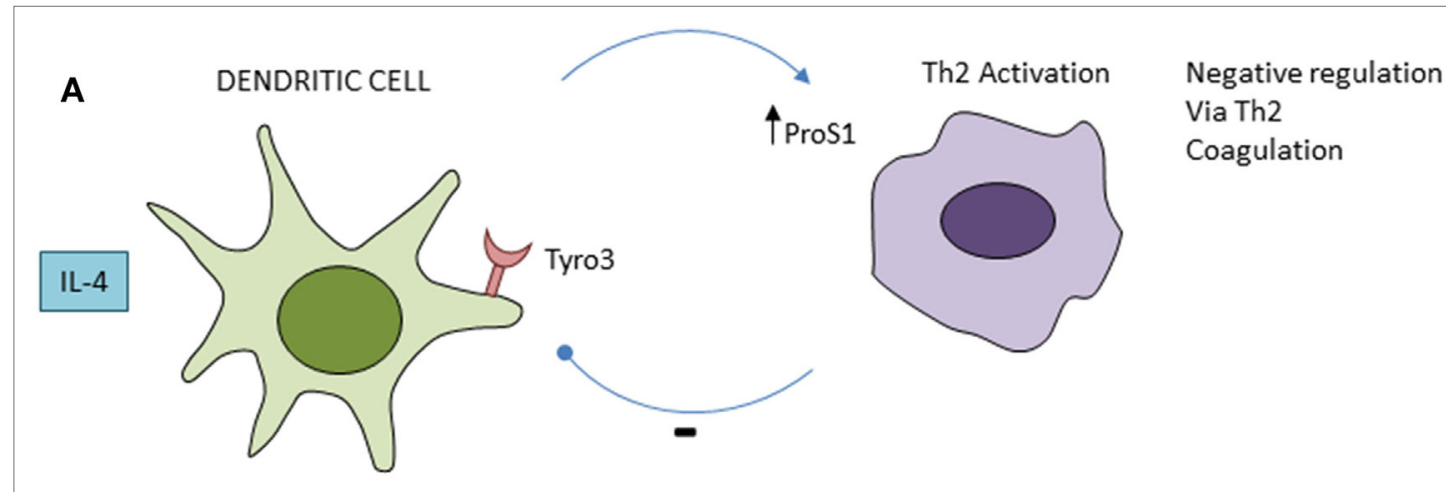

B
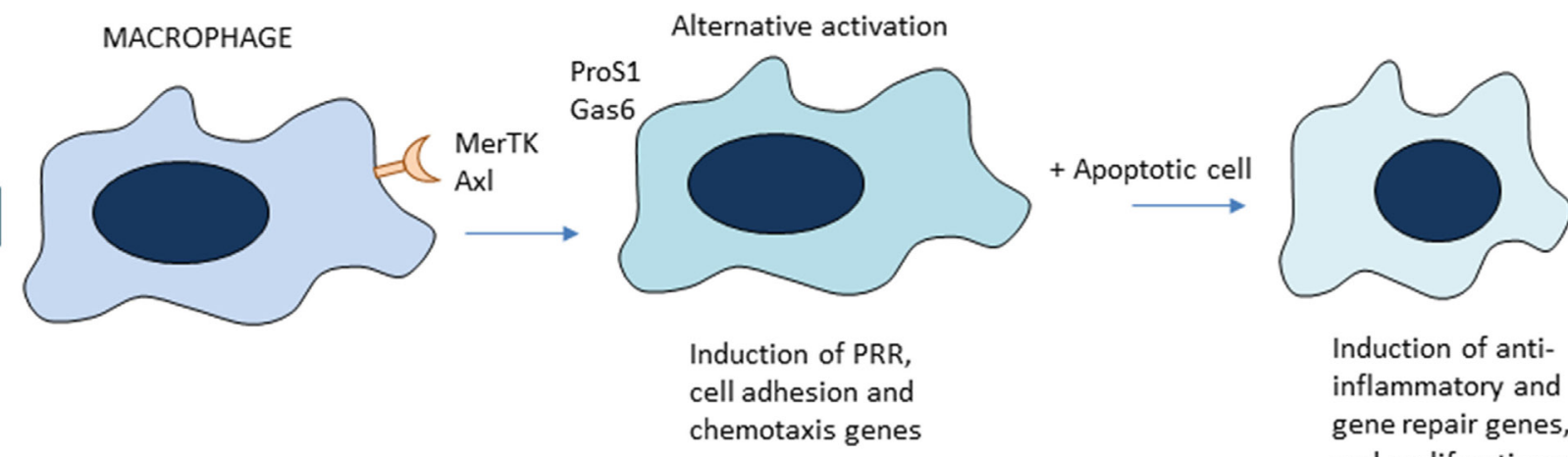

Induction of antiinflammatory and gene repair genes, and proliferation of resident macrophages

FIGURE 2 | Role of tyrosine receptor kinases Tyro 3, Axl, and MerTK family apoptotic receptors in regulation of Th2 immunity (A) and alternative activation of macrophages $\mathbf{( B )}$. See text for further details and references. 
full tissue repair program (69). If lysosomal peptides gain access to $\mathrm{MHC}$ or cytosol, cross-presentation can induce autoreactive $\mathrm{CD} 8^{+}$cytotoxic lymphocytes. Ly $6^{+}$monocytes are able to efferocytose apoptotic cells and cross-present cell-associated antigens to $\mathrm{CD}^{+} \mathrm{T}$ cells; this is enhanced by ligation of TLR7, but not TLR4 (72). Autoreactive Th17 lymphocytes can also be induced by apoptotic cell products in the context of microbial infection (73). Kleinclauss et al. reported that intravenous infusion of apoptotic spleen cells induced a tgf beta-dependent expansion of regulatory $\mathrm{T}$ lymphocytes, contributing to tolerance, induced by macrophages and not DCs (74). Saas and colleagues (21) have discussed the mechanism of early apoptotic cell infusion to prevent and limit ongoing autoimmune inflammation.

\section{CONCLUDING REMARKS}

Given the importance of the biological process of apoptotic cell clearance, it seems surprising that it might go wrong so infrequently; is there such redundancy and backup to keep it safe, or are we looking in the wrong place? Of course, we know of some autoimmune conditions, e.g., systemic lupus erythematosus (SLE), to which inefficient apoptotic cell clearance contributes; Munoz et al. (75) have discussed the role of nucleic acid and auto-antibody complexes in the pathogenesis of recurrent inflammation, resulting in production of type I interferon, a hallmark of SLE. A major effort is under way to use monoclonal antibodies directed against CD47, a "don't eat me" signal expressed by selected malignancies, to promote tumor cell ingestion by macrophages (40). A promising, safe protocol has been developed for

\section{REFERENCES}

1. Henson PM. Cell removal: efferocytosis. Annu Rev Cell Dev Biol (2017) 33:127-44. doi:10.1146/annurev-cellbio-111315-125315

2. Arandjelovic S, Ravichandran KS. Phagocytosis of apoptotic cells in homeostasis. Nat Immunol (2015) 16:907-17. doi:10.1038/ni.3253

3. Nagata S, Tanaka M. Programmed cell death and the immune system. Nat Rev Immunol (2017) 17:333-40. doi:10.1038/nri.2016.153

4. Lim JJ, Grinstein S, Roth Z. Diversity and versatility of phagocytosis: roles in innate immunity, tissue remodeling, and homeostasis. Front Cell Infect Microbiol (2017) 7:191. doi:10.3389/fcimb.2017.00191

5. Gordon S. Phagocytosis: an immunobiologic process. Immunity (2016) 44:463-75. doi:10.1016/j.immuni.2016.02.026

6. Wyllie AH, Kerr JF, Currie AR. Cell death: the significance of apoptosis. Int Rev Cytol (1980) 68:251-306. doi:10.1016/S0074-7696(08) 62312-8

7. Wallach D, Kang TB, Kovalenko A. Concepts of tissue injury and cell death in inflammation: a historical perspective. Nat Rev Immunol (2014) 14:51-9. doi:10.1038/nri3561

8. Underhill DM, Gordon S, Imhof BA, Nunez G, Bousso P. Elie Metchnikoff (1845-1916): celebrating 100 years of cellular immunology and beyond. Nat Rev Immunol (2016) 16:651-6. doi:10.1038/nri.2016.89

9. Yona S, Gordon S. From the reticuloendothelial to mononuclear phagocyte system - the unaccounted years. Front Immunol (2015) 6:328. doi:10.3389/ fimmu.2015.00328

10. Pinto SM, Hengartner MO. Cleaning up the mess: cell corpse clearance in Caenorhabditis elegans. Curr Opin Cell Biol (2012) 24:881-8. doi:10.1016/j. ceb.2012.11.002

11. Freeman SA, Grinstein S. Phagocytosis: how macrophages tune their non-professional counterparts. Curr Biol (2016) 26:R1279-82. doi:10.1016/j. cub.2016.10.059 adoptive transfer of mononuclear phagocytes that have started to engulf apoptotic cells, prophylactically, to facilitate allogeneic hematopoietic transplantation (76). It will be important to characterize the appropriate subpopulation of macrophages for such therapeutic applications. Conversely, we have good reason to believe that uptake of apoptotic HIV-infected lymphocytes by macrophages can provide a route to infection of healthy $\mathrm{CD} 4^{+}$ T cells (77).

Although the research efforts in this area are mainly based on insights of several decades ago, it would be advisable to use the more advanced methods now available to revisit the fundamental aspects of the phagocytic process. It is exciting to see the recent adoption of intravital methods to study gene expression and growth responses in vivo. The holy grail might be to extend the limited regenerative capability of hematopoiesis, intestinal epithelium, and liver more widely to other tissues. In this regard, it would be wise to use a broad comparative approach to discover the factors that shut regeneration down during evolution. Or would that risk enhancing malignant diseases (78)?

\section{AUTHOR CONTRIBUTIONS}

SG conceived and wrote the manuscript. AP reviewed and edited the manuscript and designed the figures.

\section{ACKNOWLEDGMENTS}

We thank colleagues who have sent us preprints of their current work.

12. deCathelineau AM, Henson PM. The final step in programmed cell death: phagocytes carry apoptotic cells to the grave. Essays Biochem (2003) 39:105-17. doi:10.1042/bse0390105

13. VandenBergheT,LinkermannA,Jouan-LanhouetS, WalczakH,VandenabeeleP. Regulated necrosis: the expanding network of non-apoptotic cell death pathways. Nat Rev Mol Cell Biol (2014) 15:135-47. doi:10.1038/nrm3737

14. Cookson BT, Brennan MA. Pro-inflammatory programmed cell death. Trends Microbiol (2001) 9:113-4. doi:10.1016/S0966-842X(00)01936-3

15. Brown GC, Vilalta A, Fricker M. Phagoptosis-cell death by phagocytosis-plays central roles in physiology, host defense and pathology. Curr Mol Med (2015) 15:842-51. doi:10.2174/156652401509151105130628

16. Fearnhead HO, Vandenabeele P, Vanden Berghe T. How do we fit ferroptosis in the family of regulated cell death? Cell Death Differ (2017) 24:1991-8. doi:10.1038/cdd.2017.149

17. Joly E, Hudrisier D. What is trogocytosis and what is its purpose? Nat Immunol (2003) 4:815. doi:10.1038/ni0903-815

18. Overholtzer M, Mailleux AA, Mouneimne G, Normand G, Schnitt SJ, King RW, et al. A nonapoptotic cell death process, entosis, that occurs by cell-in-cell invasion. Cell (2007) 131:966-79. doi:10.1016/j.cell.2007.10.040

19. Mevorach D, Trahtemberg U, Krispin A, Attalah M, Zazoun J, Tabib A, et al. What do we mean when we write "senescence," "apoptosis," "necrosis," or "clearance of dying cells"? Ann N Y Acad Sci (2010) 1209:1-9. doi:10.1111/j. 1749-6632.2010.05774.x

20. Henson PM, Bratton DL. Antiinflammatory effects of apoptotic cells. J Clin Invest (2013) 123:2773-4. doi:10.1172/JCI69344

21. Saas P, Bonnefoy F, Toussirot E, Perruche S. Harnessing apoptotic cell clearance to treat autoimmune arthritis. Front Immunol (2017) 8:1191. doi:10.3389/ fimmu.2017.01191

22. Trahtemberg U, Mevorach D. Apoptotic cells induced signaling for immune homeostasis in macrophages and dendritic cells. Front Immunol (2017) 8:1356. doi:10.3389/fimmu.2017.01356 
23. Gordon S, Pluddemann A. Tissue macrophages: heterogeneity and functions. BMC Biol (2017) 15:53. doi:10.1186/s12915-017-0392-4

24. Varol C, Mildner A, Jung S. Macrophages: development and tissue specialization. Аnпu Rev Immunol (2015) 33:643-75. doi:10.1146/annurevimmunol-032414-112220

25. Amit I, Winter DR, Jung S. The role of the local environment and epigenetics in shaping macrophage identity and their effect on tissue homeostasis. Nat Immunol (2016) 17:18-25. doi:10.1038/ni.3325

26. Villani AC, Satija R, Reynolds G, Sarkizova S, Shekhar K, Fletcher J, et al. Single-cell RNA-seq reveals new types of human blood dendritic cells, monocytes, and progenitors. Science (2017) 356:eah4573. doi:10.1126/science. aah4573

27. Trahtemberg U, Grau A, Tabib A, Atallah M, Krispin A, Mevorach D. Identification and characterization of two human monocyte-derived dendritic cell subpopulations with different functions in dying cell clearance and different patterns of cell death. PLoS One (2016) 11:e0162984. doi:10.1371/ journal.pone.0162984

28. Wang J, Kubes P. A reservoir of mature cavity macrophages that can rapidly invade visceral organs to affect tissue repair. Cell (2016) 165:668-78. doi:10.1016/j.cell.2016.03.009

29. Robbins CS, Chudnovskiy A, Rauch PJ, Figueiredo JL, Iwamoto Y, Gorbatov R, et al. Extramedullary hematopoiesis generates Ly-6C(high) monocytes that infiltrate atherosclerotic lesions. Circulation (2012) 125:36474. doi:10.1161/CIRCULATIONAHA.111.061986

30. Cummings RJ, Barbet G, Bongers G, Hartmann BM, Gettler K, Muniz L, et al. Different tissue phagocytes sample apoptotic cells to direct distinct homeostasis programs. Nature (2016) 539:565-9. doi:10.1038/nature20138

31. A-Gonzalez N, Quintana JA, Garcia-Silva S, Mazariegos M, Gonzalez de la Aleja A, Nicolas-Avila JA, et al. Phagocytosis imprints heterogeneity in tissue-resident macrophages. J Exp Med (2017) 214:1281-96. doi:10.1084/ jem. 20161375

32. Helming L, Gordon S. Molecular mediators of macrophage fusion. Trends Cell Biol (2009) 19:514-22. doi:10.1016/j.tcb.2009.07.005

33. Milde R, Ritter J, Tennent GA, Loesch A, Martinez FO, Gordon S, et al. Multinucleated giant cells are specialized for complement-mediated phagocytosis and large target destruction. Cell Rep (2015) 13:1937-48. doi:10.1016/j. celrep.2015.10.065

34. Martinez FO, Gordon S. The M1 and M2 paradigm of macrophage activation: time for reassessment. F1000Prime Rep (2014) 6:13. doi:10.12703/ P6-13

35. Patel AA, Zhang Y, Fullerton JN, Boelen L, Rongvaux A, Maini AA, et al. The fate and lifespan of human monocyte subsets in steady state and systemic inflammation. J Exp Med (2017) 214:1913-23. doi:10.1084/jem.20170355

36. Savill J, Dransfield I, Gregory C, Haslett C. A blast from the past: clearance of apoptotic cells regulates immune responses. Nat Rev Immunol (2002) 2:965-75. doi:10.1038/nri957

37. Medina CB, Ravichandran KS. Do not let death do us part: 'find-me' signals in communication between dying cells and the phagocytes. Cell Death Differ (2016) 23:979-89. doi:10.1038/cdd.2016.13

38. Wolf $\mathrm{Y}$, Boura-Halfon S, Cortese N, Haimon Z, Sar Shalom H, Kuperman Y, et al. Brown-adipose-tissue macrophages control tissue innervation and homeostatic energy expenditure. Nat Immunol (2017) 18:665-74. doi:10.1038/ni.3746

39. Kong Y, Janssen BJ, Malinauskas T, Vangoor VR, Coles CH, Kaufmann R, et al. Structural basis for plexin activation and regulation. Neuron (2016) 91:548-60. doi:10.1016/j.neuron.2016.06.018

40. Weiskopf K, Schnorr PJ, Pang WW, Chao MP, Chhabra A, Seita J, et al. Myeloid cell origins, differentiation, and clinical implications. Microbiol Spectr (2016) 4. doi:10.1128/microbiolspec

41. Oldenborg PA. CD47: a cell surface glycoprotein which regulates multiple functions of hematopoietic cells in health and disease. ISRN Hematol (2013) 2013:614619. doi:10.1155/2013/614619

42. Penberthy KK, Ravichandran KS. Apoptotic cell recognition receptors and scavenger receptors. Immunol Rev (2016) 269:44-59. doi:10.1111/imr.12376

43. Segawa K, Nagata S. An apoptotic 'eat me' signal: phosphatidylserine exposure. Trends Cell Biol (2015) 25:639-50. doi:10.1016/j.tcb.2015.08.003

44. Platt N, Haworth R, Darley L, Gordon S. The many roles of the class A macrophage scavenger receptor. Int Rev Cytol (2002) 212:1-40. doi:10.1016/ S0074-7696(01)12002-4
45. Han CZ, Juncadella IJ, Kinchen JM, Buckley MW, Klibanov AL, Dryden K, et al. Macrophages redirect phagocytosis by non-professional phagocytes and influence inflammation. Nature (2016) 539:570-4. doi:10.1038/nature20141

46. Wood W, Turmaine M, Weber R, Camp V, Maki RA, McKercher SR, et al. Mesenchymal cells engulf and clear apoptotic footplate cells in macrophageless PU.1 null mouse embryos. Development (2000) 127:5245-52.

47. Goodridge HS, Reyes CN, Becker CA, Katsumoto TR, Ma J, Wolf AJ, et al. Activation of the innate immune receptor Dectin-1 upon formation of a 'phagocytic synapse'. Nature (2011) 472:471-5. doi:10.1038/nature10071

48. Wood W, Martin P. Macrophage functions in tissue patterning and disease: new insights from the fly. Dev Cell (2017) 40:221-33. doi:10.1016/j. devcel.2017.01.001

49. Levin R, Hammond GR, Balla T, De Camilli P, Fairn GD, Grinstein S. Multiphasic dynamics of phosphatidylinositol 4-phosphate during phagocytosis. Mol Biol Cell (2017) 28:128-40. doi:10.1091/mbc.E16-06-0451

50. Kay JG, Grinstein S. Phosphatidylserine-mediated cellular signaling. Adv Exp Med Biol (2013) 991:177-93. doi:10.1007/978-94-007-6331-9_10

51. Billings EA, Lee CS, Owen KA, D'Souza RS, Ravichandran KS, Casanova JE. The adhesion GPCR BAI1 mediates macrophage ROS production and microbicidal activity against gram-negative bacteria. Sci Signal (2016) 9:ra14. doi:10.1126/scisignal.aac6250

52. Hamann J, Hsiao CC, Lee CS, Ravichandran KS, Lin HH. Adhesion GPCRs as modulators of immune cell function. Handb Exp Pharmacol (2016) 234:329-50. doi:10.1007/978-3-319-41523-9_15

53. Levin R, Grinstein S, Canton J. The life cycle of phagosomes: formation, maturation, and resolution. Immunol Rev (2016) 273:156-79. doi:10.1111/ imr.12439

54. Lavin Y, Winter D, Blecher-Gonen R, David E, Keren-Shaul H, Merad M, et al. Tissue-resident macrophage enhancer landscapes are shaped by the local microenvironment. Cell (2014) 159:1312-26. doi:10.1016/j.cell.2014.11.018

55. Roberts AW, Lee BL, Deguine J, John S, Shlomchik MJ, Barton GM. Tissueresident macrophages are locally programmed for silent clearance of apoptotic cells. Immunity (2017) 47:913.e-27.e. doi:10.1016/j.immuni.2017.10.006

56. Baratin M, Simon L, Jorquera A, Ghigo C, Dembele D, Nowak J, et al. T cell zone resident macrophages silently dispose of apoptotic cells in the lymph node. Immunity (2017) 47(349-62):e5. doi:10.1016/j.immuni.2017.07.019

57. Bannard O, Cyster JG. Germinal centers: programmed for affinity maturation and antibody diversification. Curr Opin Immunol (2017) 45:21-30. doi:10.1016/j.coi.2016.12.004

58. Weavers H, Evans IR, Martin P, Wood W. Corpse engulfment generates a molecular memory that primes the macrophage inflammatory response. Cell (2016) 165:1658-71. doi:10.1016/j.cell.2016.04.049

59. Moorlag S, Roring RJ, Joosten LAB, Netea MG. The role of the interleukin-1 family in trained immunity. Immunol Rev (2018) 281:28-39. doi:10.1111/ imr.12617

60. Askew K, Li K, Olmos-Alonso A, Garcia-Moreno F, Liang Y, Richardson P, et al. Coupled proliferation and apoptosis maintain the rapid turnover of microglia in the adult brain. Cell Rep (2017) 18:391-405. doi:10.1016/j. celrep.2016.12.041

61. Fogarty CE, Diwanji N, Lindblad JL, Tare M, Amcheslavsky A, Makhijani K, et al. Extracellular reactive oxygen species drive apoptosis-induced proliferation via Drosophila macrophages. Curr Biol (2016) 26:575-84. doi:10.1016/j. cub.2015.12.064

62. Ueno M, Fujita Y, Tanaka T, Nakamura Y, Kikuta J, Ishii M, et al. Layer V cortical neurons require microglial support for survival during postnatal development. Nat Neurosci (2013) 16:543-51. doi:10.1038/nn.3358

63. Brown GC, Neher JJ. Microglial phagocytosis of live neurons. Nat Rev Neurosci (2014) 15:209-16. doi:10.1038/nrn3710

64. Kawane K, Fukuyama H, Kondoh G, Takeda J, Ohsawa Y, Uchiyama Y, et al. Requirement of DNase II for definitive erythropoiesis in the mouse fetal liver. Science (2001) 292:1546-9. doi:10.1126/science.292.5521.1546

65. Godwin JW, Pinto AR, Rosenthal NA. Macrophages are required for adult salamander limb regeneration. Proc Natl Acad Sci U S A (2013) 110:9415-20. doi:10.1073/pnas.1300290110

66. Yun $\mathrm{MH}$, Davaapil H, Brockes JP. Recurrent turnover of senescent cells during regeneration of a complex structure. Elife (2015) 4. doi:10.7554/eLife. 05505

67. Bryant DM, Johnson K, DiTommaso T, Tickle T, Couger MB, PayzinDogru D, et al. A tissue-mapped axolotl de novo transcriptome enables 
identification of limb regeneration factors. Cell Rep (2017) 18:762-76. doi:10.1016/j.celrep.2016.12.063

68. Zanoni I, Tan Y, Di Gioia M, Springstead JR, Kagan JC. By capturing inflammatory lipids released from dying cells, the receptor CD14 induces inflammasome-dependent phagocyte hyperactivation. Immunity (2017) 47:697.e-709.e. doi:10.1016/j.immuni.2017.09.010

69. Bosurgi L, Cao YG, Cabeza-Cabrerizo M, Tucci A, Hughes LD, Kong Y, et al. Macrophage function in tissue repair and remodeling requires IL-4 or IL-13 with apoptotic cells. Science (2017) 356:1072-6. doi:10.1126/science.aai8132

70. Rothlin CV, Carrera-Silva EA, Bosurgi L, Ghosh S. TAM receptor signaling in immune homeostasis. Annu Rev Immunol (2015) 33:355-91. doi:10.1146/ annurev-immunol-032414-112103

71. Chan PY, Carrera-Silva EA, De Kouchkovsky D, Joannas LD, Hao L, Hu D, et al. The TAM family receptor tyrosine kinase TYRO3 is a negative regulator of type 2 immunity. Science (2016) 352:99-103. doi:10.1126/science.aaf1358

72. Larson SR, Atif SM, Gibbings SL, Thomas SM, Prabagar MG, Danhorn T, et al. Ly6C(+) monocyte efferocytosis and cross-presentation of cell-associated antigens. Cell Death Differ (2016) 23:997-1003. doi:10.1038/cdd.2016.24

73. Campisi L, Barbet G, Ding Y, Esplugues E, Flavell RA, Blander JM. Apoptosis in response to microbial infection induces autoreactive TH17 cells. Nat Immunol (2016) 17:1084-92. doi:10.1038/ni.3512

74. Kleinclauss F, Perruche S, Masson E, de Carvalho Bittencourt M, Biichle S, Remy-Martin JP, et al. Intravenous apoptotic spleen cell infusion induces a TGF-beta-dependent regulatory T-cell expansion. Cell Death Differ (2006) 13:41-52. doi:10.1038/sj.cdd.4401699
75. Munoz LE, Lauber K, Schiller M, Manfredi AA, Herrmann M. The role of defective clearance of apoptotic cells in systemic autoimmunity. Nat Rev Rheumatol (2010) 6:280-9. doi:10.1038/nrrheum.2010.46

76. Mevorach D, Zuckerman T, Reiner I, Shimoni A, Samuel S, Nagler A, et al. Single infusion of donor mononuclear early apoptotic cells as prophylaxis for graft-versus-host disease in myeloablative HLA-matched allogeneic bone marrow transplantation: a phase I/IIa clinical trial. Biol Blood Marrow Transplant (2014) 20:58-65. doi:10.1016/j.bbmt.2013.10.010

77. Baxter AE, Russell RA, Duncan CJ, Moore MD, Willberg CB, Pablos JL, et al. Macrophage infection via selective capture of HIV-1-infected CD4+ T cells. Cell Host Microbe (2014) 16:711-21. doi:10.1016/j.chom.2014.10.010

78. Galluzzi L, Buque A, Kepp O, Zitvogel L, Kroemer G. Immunogenic cell death in cancer and infectious disease. Nat Rev Immunol (2017) 17:97-111. doi:10.1038/nri.2016.107

Conflict of Interest Statement: The authors declare that the research was conducted in the absence of any commercial or financial relationships that could be construed as a potential conflict of interest.

Copyright (C) 2018 Gordon and Plüddemann. This is an open-access article distributed under the terms of the Creative Commons Attribution License (CC BY). The use, distribution or reproduction in other forums is permitted, provided the original author(s) and the copyright owner are credited and that the original publication in this journal is cited, in accordance with accepted academic practice. No use, distribution or reproduction is permitted which does not comply with these terms. 